\title{
To Splice or to Transcribe: SKIP- Mediated Environmental Fitness and Development in Plants
}

\author{
Ying Cao and Ligeng $\mathrm{Ma}^{*}$ \\ College of Life Sciences, RNA Center, Capital Normal University, Beijing, China
}

Gene expression in eukaryotes is controlled at multiple levels, including transcriptional and post-transcriptional levels. The transcriptional regulation of gene expression is complex and includes the regulation of the initiation and elongation phases of transcription. Meanwhile, the post-transcriptional regulation of gene expression includes precursor messenger RNA (pre-mRNA) splicing, 5' capping, and 3' polyadenylation. Among these events, premRNA splicing, conducted by the spliceosome, plays a key role in the regulation of gene expression, and the efficiency and precision of pre-mRNA splicing are critical for gene function. Ski-interacting protein (SKIP) is an evolutionarily conserved protein from yeast to humans. In plants, SKIP is a bifunctional regulator that works as a splicing factor as part of the spliceosome and as a transcriptional regulator via interactions with the transcriptional regulatory complex. Here, we review how the functions of SKIP as a splicing factor and a transcriptional regulator affect environmental fitness and development in plants.

Edited by:

Craig G. Simpson, The James Hutton Institute, United Kingdom

Reviewed by:

Misato Ohtani,

Nara Institute of Science and Technology (NAIST), Japan Yingxiang Wang,

Fudan University, China

*Correspondence: Ligeng Ma

ligeng.ma@cnu.edu.cn

Specialty section: This article was submitted to Plant Physiology,

a section of the journal

Frontiers in Plant Science

Received: 17 June 2019 Accepted: 04 September 2019 Published: 03 October 2019

Citation:

Cao Y and Ma L (2019) To Splice or to Transcribe: SKIP-Mediated

Environmental Fitness and

Development in Plants.

Front. Plant Sci. 10:1222.

doi: 10.3389/fp/s.2019.01222
Keywords: SKIP, alternative splicing, transcriptional regulator, splicing factor, environmental fitness, plant development

\section{INTRODUCTION AND GENE EXPRESSION REGULATION}

Due to their sessile nature, plants must respond to both the external environment and internal signals to regulate their environmental fitness and development. To respond to these signals in a precise manner, gene expression must be tightly controlled both temporally and spatially. Gene expression is regulated at multiple levels, but most regulation occurs at the transcriptional and posttranscriptional levels (reviewed in Licatalosi and Darnell, 2010). This allows a gene to be expressed at the correct time, in specific cells, and with the appropriate abundance to support its function.

Transcriptional regulation is crucial for controlling the temporal and spatial expression of a gene, as well as the abundance of precursor messenger RNA (pre-mRNA) molecules. In eukaryotes, messenger RNAs (mRNAs) are transcribed by RNA polymerase II (Pol II) in a complicated process that includes initiation, elongation, and termination steps. The regulation of gene expression at the transcriptional level occurs mainly at the initiation and elongation stages (reviewed in Kwak and Lis, 2013; Jonkers and Lis, 2015; Sainsbury et al., 2015). In the initiation stage, Pol II with an unphosphorylated C-terminal domain (CTD) forms a pre-initiation complex by associating with transcription factors and mediators (reviewed in Hsin and Manley, 2012; Sainsbury et al., 2015; Hantsche and Cramer, 2017). Transcription initiation also requires interactions with cis-elements in the genomic DNA sequence and changes in chromatin structure and nucleosome position via epigenetic modifications (reviewed in Kouzarides, 2007; Matzke et al., 2009; Bonasio and Shiekhattar, 2014; Voss and Hager, 2014; Sainsbury et al., 2015; Lawrence et al., 2016; Jeronimo and Robert, 2017). The elongation phase is regulated by multiple elongation factors, including Pol 
II-associated factor 1 complex (Paf1c), and additional factors that influence the epigenetic modification and higher-order structure of chromatin, the phosphorylation status of the Pol II CTD, and the eventual pause and release of Pol II (reviewed in Li et al., 2007; Gilchrist et al., 2010; Hajheidari et al., 2013; Tessarz and Kouzarides, 2014; Van Lijsebettens and Grasser, 2014; Lawrence et al., 2016; Van Oss et al., 2017).

The products transcribed by Pol II from a DNA template require processing to form stable, mature mRNAs. The regulation of pre-mRNA processing at the post-transcriptional level affects the abundance of functional mature mRNAs; thus, it affects both gene expression and function. Post-transcriptional pre-mRNA processing involves $5^{\prime}$ capping mediated by $5^{\prime}$ capping enzymes at the $5^{\prime}$ end of the pre-mRNA, splicing by the spliceosome to remove introns from the pre-mRNA, and $3^{\prime}$ polyadenylation mediated by the $3^{\prime}$ polyadenylation complex at the $3^{\prime}$ end of the pre-mRNA. In addition to these events, pre-mRNA alternative splicing plays a key role in the post-transcriptional regulation of gene expression. By using different splice sites, one pre-mRNA can be processed to multiple transcripts, thus increasing the complexity of the transcriptome and proteome (reviewed in Reddy, 2007; Keren et al., 2010; Syed et al., 2012; Lee and Rio, 2015). Consequently, incorrect splicing of a pre-mRNA can decrease the amount of functional mature mRNA or lead to the production of toxic proteins that may perturb normal cellular processes (reviewed in Reddy, 2007; Braunschweig et al., 2013). The incorrectly spliced variants with a premature termination codon may activate mRNA degradation through the nonsensemediated decay (NMD) pathway to prevent the formation of nonfunctional or aberrant proteins (reviewed in He and Jacobson, 2015). Therefore, efficient and precise pre-mRNA splicing is crucial to protect gene function (reviewed in Reddy, 2007; Moore and Proudfoot, 2009; Syed et al., 2012; Staiger and Brown, 2013). Accurate splicing of an intron depends on both short consensus sequence elements around the intron and correct assembly of the components of the spliceosome around the intron's splice sites (reviewed in Wahl et al., 2009; Lee and Rio, 2015).

The spliceosome, which is responsible for pre-mRNA splicing, is a large and highly dynamic protein complex. Specific splicing factors are sequentially recruited to and released from splice sites to mediate efficient splicing. Ski-interacting protein (SKIP), a component of the spliceosome-associated NineTeen complex (NTC), is required to catalyze the first and second transesterification reactions of pre-mRNA splicing in yeast and human cells (Albers et al., 2003; Figueroa and Hayman, 2004; Bessonov et al., 2008; Chen et al., 2011; Schneider et al., 2015; Zhang et al., 2017). In addition, SKIP is a transcriptional coregulator for the expression of some genes in human cells (Laduron et al., 2004; Brès et al., 2005; Brès et al., 2009; Chen et al., 2011). SKIP protein is conserved from yeast to humans including plants. It acts both as a splicing factor to regulate precise and efficient pre-mRNA splicing and as a transcriptional regulator of gene transcription in Arabidopsis. This review focuses on the regulatory functions of SKIP that control gene expression at the transcriptional and post-transcriptional levels to mediate the environmental fitness and development of plants.

\section{SKIP MEDIATES PLANT ENVIRONMENTAL FITNESS BY REGULATING ALTERNATIVE SPLICING}

Flowering is an important developmental phase transition in higher plants. To regulate flowering time, plants integrate endogenous and environmental signals, which are important for survival and crop productivity. To find new components of the flowering time control pathway in Arabidopsis, a genetic screen was performed using a T-DNA insertion library for altered flowering time mutants, and a mutant, eip1-1, that exhibits an early flowering phenotype under long- and short-day conditions was isolated (Wang et al., 2012). Such a photoperiod-insensitive flowering time defect is characteristic of circadian clock-defective mutants. Consistent with this, eip1-1 exhibits a lengthened circadian period in a temperaturesensitive manner. Compared to the $\sim 24$-h circadian period of wild-type plants, the circadian period of eip1-1 is lengthened by $\sim 2.4 \mathrm{~h}$ due to changes in the rhythmic expression of the core oscillator genes CIRCADIAN CLOCK-ASSOCIATED 1, LATE ELONGATED HYPOCOTYL, and TIMING OF CAB EXPRESSION 1 (Wang et al., 2012). Map-based cloning revealed that a mutation in Atlg77180, which encodes SKIP, is responsible for the flowering time and circadian period defects observed in eip1-1 (which was therefore renamed skip-1). There is a 22-nucleotide deletion at the C-terminus of the SKIP locus, which disrupts the integrity of the SKIP protein and impairs SKIP function in skip-1 plants (Wang et al., 2012).

SKIP is a single-copy gene in the Arabidopsis genome encoding a protein of 613 amino acids with three structural domains: the N-terminus (amino acids 1-185), SNW domain (amino acids 186-416), and C-terminus (amino acids 417-613) (Figure 1; Li et al., 2016). The plant SKIP protein sequence is highly similar to that of its ortholog (SKIP) in humans and pre-mRNA processing (Prp) 45 in yeast (Wang et al., 2012). SKIP localizes to the nucleus using two nuclear localization signals (NLSs), which lie in the SNW domain and C-terminus, respectively (Figure 1; Lim et al., 2010; Li et al., 2016).

In Arabidopsis, SKIP co-localizes with the spliceosome components U1 SMALL NUCLEAR RIBONUCLEOPROTEIN70K (U1-70K) (Golovkin and Reddy, 1996) and SERINE/ ARGININE RICH 45 (SR45) (Day et al., 2012) in nuclear bodies (Wang et al., 2012). SKIP associates closely with SR45 and other NTC components, facilitating its integration into the spliceosome (Wang et al., 2012; Li et al., 2016). Mutations in SKIP decrease the splicing efficiency of the spliceosome and can cause genomewide alternative splicing defects (Wang et al., 2012; Feng et al., 2015). SKIP is required for $5^{\prime}$ and $3^{\prime}$ splice site recognition or cleavage; novel splicing events have been reported in skip mutant plants with decreased usage of the dominant GU and AG, respectively, at 5' and 3' splice sites (Wang et al., 2012; Feng et al., 2015). Therefore, SKIP is a splicing factor that regulates the efficient and precise splicing of pre-mRNAs on a genome-wide scale in Arabidopsis.

In addition, SKIP binds directly to the pre-mRNAs of clock genes, including PSEUDO-RESPONSE REGULATOR 7 (PRR7) 
SKIP

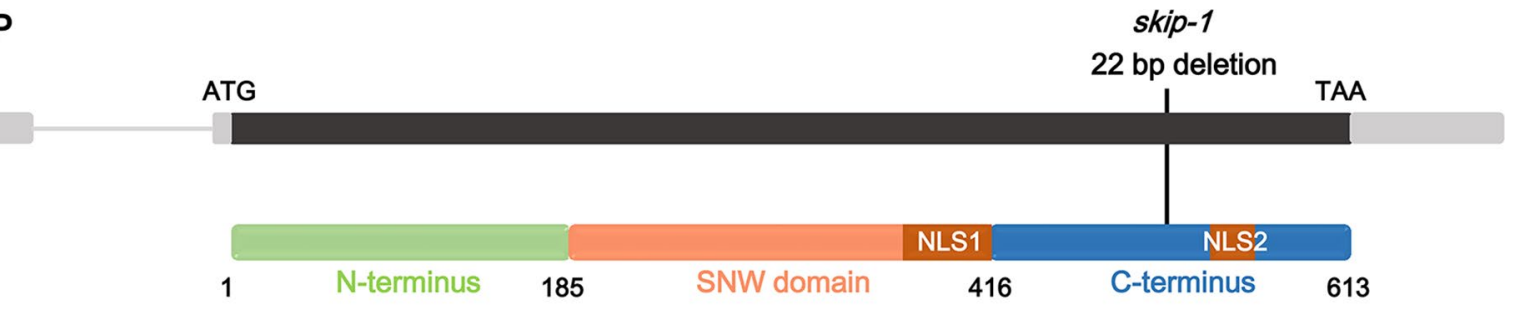

100 aa; 300 bp

FIGURE 1 | The domain structure of ski-interacting protein (SKIP) and the location of skip-1 mutant. Gray box: UTR; gray line: intron; black box: exon; colored boxes: domain feature of the protein; black line: the mutation site of the mutant.

and PRR9, to regulate their accurate splicing and mRNA maturation (Wang et al., 2012). Compared to wild-type plants, skip-1 plants show increased levels of aberrantly spliced variants of PRR7 and PRR9 and decreased levels of functional, fully spliced $P R R 7$ and PRR9 mRNAs. The reduced levels of functional PRR7 and PRR9 mRNAs in skip-1 contribute to its lengthened circadian period phenotype (Wang et al., 2012). Therefore, SKIP mediates the circadian clock by regulating the alternative splicing of clock genes. These findings demonstrate that posttranscriptional regulation plays vital roles in controlling the circadian clock (Sanchez et al., 2010; Jones et al., 2012; Wang et al., 2012; Li et al., 2019).

SKIP also regulates plant response to abiotic stress (Hou et al., 2009; Zhang Y, et al., 2013; Feng et al., 2015; Li et al., 2016; Li et al., 2019). Mutations in SKIP have been shown to cause hypersensitivity to salt or osmotic stress in Arabidopsis. Compared to wild-type plants, skip-1 plants exhibit a significantly decreased germination rate, survival rate, and relative root growth under high-salt or drought conditions (Feng et al., 2015; Li et al., 2016). Meanwhile, ectopic expression of SKIP results in increased tolerance to salt or dehydration (Lim et al., 2010). In Arabidopsis, salt stress induces genome-wide alternative splicing events, most of which are regulated by SKIP (Feng et al., 2015). SKIP mediates the recognition or cleavage of $5^{\prime}$ alternative donor sites and $3^{\prime}$ alternative acceptor sites, and it is essential for alternative gene splicing under conditions of salt stress (Feng et al., 2015). Transcripts of several salt tolerance-related genes, including $\mathrm{NA}^{+}$/ $H^{+}$EXCHANGER 1 (NHX1), CALCINEURIN B-LIKE PROTEIN 1 (CBL1), DELTA1-PYRROLINE-5-CARBOXYLATE SYNTHASE 1 (P5CS1), RARE-COLD-INDUCIBLE 2A (RCI2A), and PROTEIN $S$-ACYL TRANSFERASE 10 (PAT10), are aberrantly spliced in skip-1 under salt stress conditions, decreasing the abundance of fully spliced mRNAs. Premature termination during the translation of these aberrantly spliced variants in skip-1 reduces the level of functional proteins, resulting in salt hypersensitivity (Feng et al., 2015; Li et al., 2016; Li et al., 2019). Therefore, SKIP is necessary for plants to respond to salt or drought stress, and alternative gene splicing is crucial for plants to respond to environmental cues (Hou et al., 2009; Zhang Y, et al., 2013; Feng et al., 2015; Li et al., 2016; Li et al., 2019; reviewed in Filichkin et al., 2015; Laloum et al., 2018).
In summary, SKIP is a splicing factor that is essential for the precise and efficient splicing of pre-mRNAs on a genome-wide scale, and it mediates the circadian clock and resistance to salt or drought stress by regulating the alternative splicing of clock and salt tolerance-related genes in plants.

\section{SKIP MEDIATES THE FLORAL TRANSITION BY REGULATING TRANSCRIPTION}

Initially, skip-1 was characterized as a photoperiod-insensitive early flowering mutant. As defects in the circadian clock may cause changes in the temporal expression of CONSTANS (CO), which regulates FLOWERING LOCUS T $(F T)$ transcription and affects flowering time (reviewed in Yanovsky and Kay, 2003; Song et al., 2015; Shim et al., 2017), some speculate whether SKIP regulates flowering time by regulating the circadian expression of $\mathrm{CO}$. However, no obvious change in the expression of $\mathrm{CO}$ was observed in skip-1 (Cao et al., 2015), suggesting that the early flowering phenotype of skip-1 is not caused by a circadian clock defect.

FLOWERING LOCUS C (FLC) is a MADS-box transcription factor that dose-dependently suppresses the floral transition (reviewed in He and Amasino, 2005; Michaels, 2009; RomeraBranchat et al., 2014; Whittaker and Dean, 2017). Both sense and antisense (COOLAIR) transcripts of FLC undergo alternative splicing (Marquardt et al., 2014; Mahrez et al., 2016); moreover, temperature-dependent alternative splicing of FLOWERING LOCUS M (FLM), which changes the ratio of FLM- $\beta$ to FLM- $\delta$, plays a vital role in regulating the temperature-dependent floral transition (Lee et al., 2013; Posé et al., 2013). Given that SKIP is a splicing factor that regulates genome-wide pre-mRNA splicing in Arabidopsis, it was suggested that SKIP is essential for the alternative splicing of sense and antisense FLC transcripts, or FLM pre-mRNA, to regulate the level of functional, mature mRNAs in the control of flowering time. However, splicing defects in FLC sense and COOLAIR transcripts were not observed in skip-1 (Cao et al., 2015). In addition, even though SKIP is required for the alternative splicing of $F L M$, the alternative splicing pattern of $F L M$ pre-mRNA (i.e., the ratio of FLM- $\beta$ to FLM- $\delta$ ) in response 
to temperature changes was not obviously affected in skip-1 (Cao et al., 2015). Thus, SKIP is not required for the accurate splicing of FLC or COOLAIR pre-mRNA. Instead, FLC transcription (i.e., the level of unspliced FLC mRNA) is significantly repressed in skip-1; this is reflected in the obvious repression of mature FLC transcripts and the early flowering phenotype observed in skip-1 under different photoperiod and temperature conditions (Cao et al., 2015; Li et al., 2016; Li et al., 2019). Thus, SKIP activates FLC expression at the transcriptional level in a photoperiod- and temperature-independent manner, and it represses flowering time by promoting FLC transcription.

To determine how SKIP activates FLC transcription, thereby repressing flowering, a yeast two-hybrid screen was performed to identify factors that interact with SKIP. ELF7, a Paf1c component that regulates transcription elongation, was found to interact with SKIP (Cao et al., 2015). Paflc represses flowering by promoting the trimethylation of histone $\mathrm{H} 3$ at lysine 4 on FLC chromatin and activating FLC transcription (He et al., 2004; Oh et al., 2004; Yu and Michaels, 2010). It was verified that SKIP interacts physically and genetically with ELF7 to regulate flowering time in Arabidopsis (Cao et al., 2015; Li et al., 2016). SKIP and ELF7 bind directly to FLC/MAFs chromatin and promote histone $\mathrm{H} 2 \mathrm{~B}$ monoubiquitination, increasing the trimethylation of histone $\mathrm{H} 3$ at lysine 4 and FLC/MAFs transcriptional activation, thereby repressing the floral transition in wild-type plants (Cao et al.,
2015). During this process, SKIP functions as a co-transcriptional activator, mediating plant flowering via the regulation of FLC/ $M A F s$ transcription. Therefore, SKIP can promote the transcription of specific genes as a co-transcriptional activator in plants.

\section{CONCLUSION AND PROSPECTS}

Plants respond to internal and environmental signals affecting their development and environmental fitness by accurately regulating gene expression at the transcriptional and posttranscriptional levels. SKIP has a dual function in plants: it acts as a splicing factor to control efficient and precise pre-mRNA splicing on a genome-wide scale by interacting with other spliceosome components (e.g., SR45) and integrating into the spliceosome, and it is required for $5^{\prime}$ and $3^{\prime}$ splice site recognition or cleavage (Wang et al., 2012; Feng et al., 2015). SKIP affects the circadian clock and plant responses to salt stress by regulating the accurate splicing of certain clock- and salt tolerance-related genes (Wang et al., 2012; Feng et al., 2015; Li et al., 2016; Li et al., 2019). SKIP also functions as a transcriptional co-regulator by interacting with other transcriptional regulators (e.g., Paf1c), and it mediates the floral transition (Cao et al., 2015; Li et al., 2016; Li et al., 2019). Therefore, SKIP precisely regulates gene expression at the transcriptional and post-transcriptional levels to mediate plant development and environmental fitness (Figure 2).

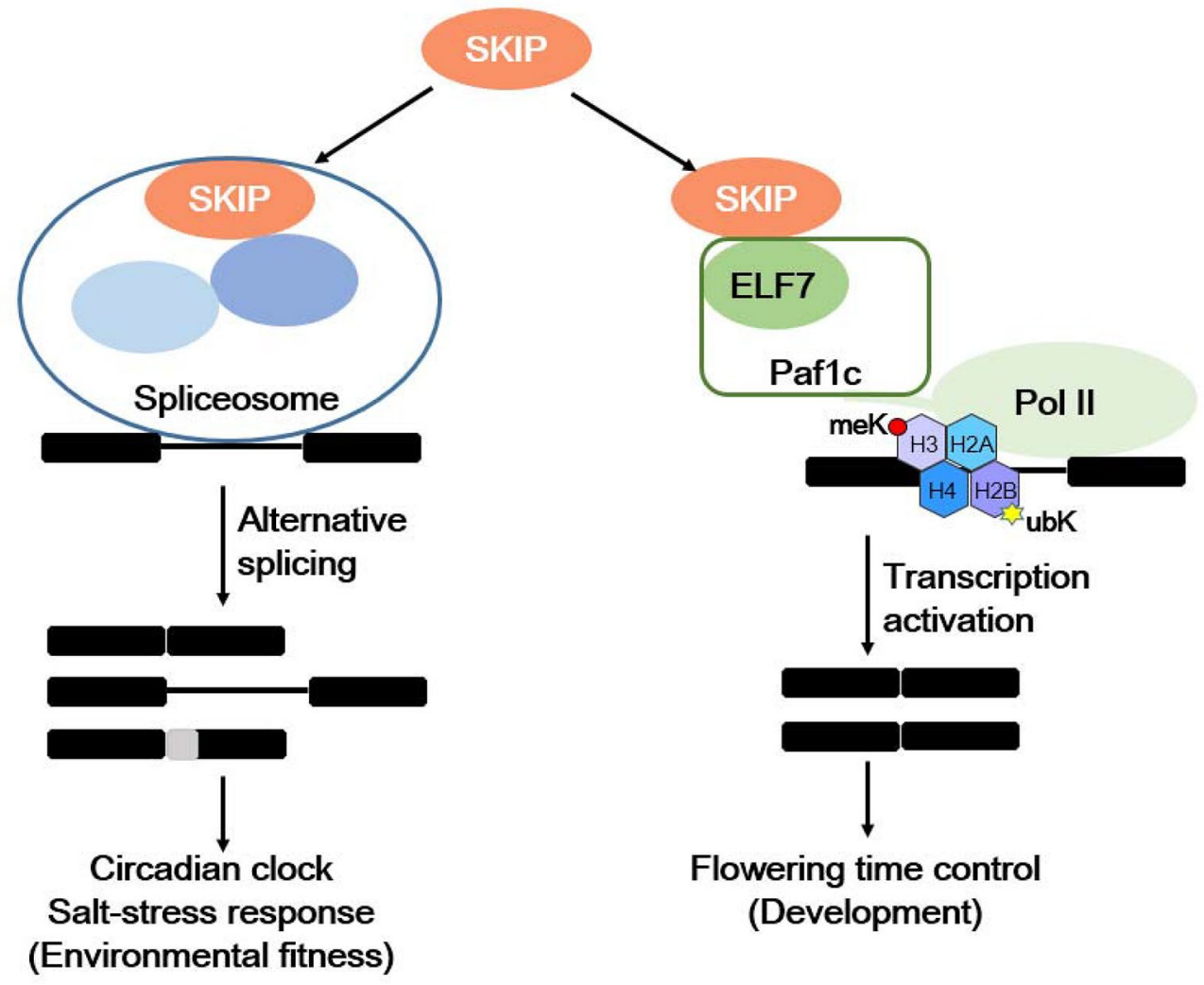

FIGURE 2 | The dual functions of SKIP in mediating environmental fitness and development in plants. SKIP is a splicing factor that regulates the alternative splicing of clock and stress tolerance-related genes in order to mediate the circadian clock and stress responses. It also functions as a transcriptional coactivator by interacting with RNA polymerase II-associated factor 1 complex (Paf1c) to activate FLC/MAFs transcription and mediate the floral transition. 
In addition to SKIP, several other splicing factors are believed to have dual functions in splicing and transcription in Arabidopsis. For example, the RNA-binding protein SR45, first identified as an interacting partner of U1-70K and an essential splicing factor in plants (Golovkin and Reddy, 1999; Ali et al., 2007; Carvalho et al., 2016), was reported to be recruited to FLC chromatin by VIVIPAROUS 1/ABI3-LIKE factor 1 (VAL1), a transcriptional repressor that further recruits the transcriptional repression complex plant homeodomain-polycomb repressive complex 2 (PHD-PRC2), resulting in decreased histone acetylation of FLC chromatin and FLC transcriptional silencing during vernalization (Qüesta et al., 2016). This suggests that SR45 is a component of the transcriptional repression complex that suppresses FLC expression in Arabidopsis. In addition, SR45 participates in a small interfering RNA-directed DNA methylation (RdDM) pathway that mediates gene silencing in Arabidopsis (Ausin et al., 2012). ZINC-FINGER AND OCRE DOMAIN-CONTAINING PROTEIN 1 (ZOP1), a premRNA splicing factor, associates with such typical spliceosome components as U1-70K, STABILIZED 1 (STA1, a PRP6-like splicing factor), and RNA-DIRECTED DNA METHYLATION 16 (RDM16, pre-mRNA-splicing factor 3) and is required for RdDM-mediated transcriptional gene silencing (Dou et al., 2013; Huang et al., 2013; Zhang CJ, et al., 2013). Furthermore, PRP31, a conserved pre-mRNA splicing factor, associates with STA1, ZOP1, and RDM16 to regulate transcriptional gene silencing in a manner independent of the RdDM pathway (Du et al., 2015). Therefore, it appears that SKIP is not the only factor required for the regulation of gene expression at both the transcriptional and post-transcriptional levels. Bifunctional splicing factors may provide an effective way for plants to coordinate their responses to environmental and internal signals in order to adjust their development and environmental adaptation via

\section{REFERENCES}

Albers, M., Diment, A., Muraru, M., Russell, C. S., and Beggs, J. D. (2003). Identification and characterization of Prp45p and Prp46p, essential pre-mRNA splicing factors. RNA 9, 138-150. doi: 10.1261/rna.2119903

Ali, G. S., Palusa, S. G., Golovkin, M., Prasad, J., Manley, J. L., and Reddy, A. S. (2007). Regulation of plant developmental processes by a novel splicing factor. PLoS ONE 2, e471. doi: 10.1371/journal.pone.0000471

Ausin, I., Greenberg, M. V., Li, C. F., and Jacobsen, S. E. (2012). The splicing factor SR45 affects the RNA-directed DNA methylation pathway in Arabidopsis. Epigenetics 7, 29-33. doi: 10.4161/epi.7.1.18782

Bai, R., Yan, C., Wan, R., Lei, J., and Shi, Y. (2017). Structure of the post-catalytic spliceosome from Saccharomyces cerevisiae. Cell 171, 1589-1598. doi: 10.1016/j. cell.2017.10.038

Bessonov, S., Anokhina, M., Will, C. L., Urlaub, H., and Lührmann, R. (2008). Isolation of an active step I spliceosome and composition of its RNP core. Nature 452, 846-850. doi: 10.1038/nature06842

Bonasio, R., and Shiekhattar, R. (2014). Regulation of transcription by long noncoding RNAs. Annu. Rev. Genet. 48, 433-455. doi: 10.1146/annurev-genet-120213-092323

Braunschweig, U., Gueroussov, S., Plocik, A. M., Graveley, B. R., and Blencowe, B. J. (2013). Dynamic integration of splicing within gene regulatory pathways. Cell 152, 1252-1269. doi: 10.1016/j.cell.2013.02.034

Brès, V., Gomes, N., Pickle, L., and Jones, K. A. (2005). A human splicing factor, SKIP, associates with P-TEFb and enhances transcription elongation by HIV-1 Tat. Genes Dev. 19, 1211-1226. doi: 10.1101/gad.1291705 accurate gene expression regulation at the transcriptional and post-transcriptional levels.

Resolved structures of the spliceosome from yeast and human cells indicate that SKIP is intrinsically highly disordered; it serves as a scaffold protein and interacts directly with other necessary components to facilitate splicing by promoting spliceosome assembly (Yan et al., 2015; Bai et al., 2017; Zhang et al., 2017; Zhang et al., 2018). It will be interesting to determine the functions of SKIP in transcriptional complex assembly (e.g., Paf1c-SKIP) and transcriptional regulation in plants. In addition, as transcription is usually coupled with splicing (reviewed in Naftelberg et al., 2015; Saldi et al., 2016; Herzel et al., 2017) and given that SKIP is integrated into both the spliceosome and transcriptional complexes (Wang et al., 2012; Cao et al., 2015; Li et al., 2016; Li et al., 2019), it should be investigated whether SKIP mediates the coupling of transcription and splicing in Arabidopsis.

\section{AUTHOR CONTRIBUTIONS}

YC and LM wrote the manuscript.

\section{FUNDING}

This work was supported by grants from the National Natural Science Foundation of China (31770247 and 31600248) and the Innovation Research Team of Beijing Municipal Government Science Foundation (IDHT20170513).

\section{ACKNOWLEDGMENTS}

We thank Dr. Jessica Habashi for critical reading of the manuscript.

Brès, V., Yoshida, T., Pickle, L., and Jones, K. A. (2009). SKIP interacts with c-Myc and Menin to promote HIV-1 Tat transactivation. Mol. Cell. 36, 75-87. doi: 10.1016/j.molcel.2009.08.015

Cao, Y., Wen, L. G., Wang, Z., and Ma, L. G. (2015). SKIP interacts with the Pafl complex to regulate flowering via the activation of FLC transcription in Arabidopsis. Mol. Plant. 8, 1816-1819. doi: 10.1016/j.molp.2015.09.004

Carvalho, R. F., Szakonyi, D., Simpson, C. G., Barbosa, I. C., Brown, J. W., BaenaGonzález, E., et al. (2016). The Arabidopsis SR45 splicing factor, a negative regulator of sugar signaling, modulates SNF1-related protein kinase 1 stability. Plant Cell. 28, 1910-1925. doi: 10.1105/tpc.16.00301

Chen, Y., Zhang, L., and Jones, K. A. (2011). SKIP counteracts p53-mediated apoptosis via selective regulation of p21Cip1 mRNA splicing. Genes Dev. 25, 701-716. doi: 10.1101/gad.2002611

Day, I. S., Golovkin, M., Palusa, S. G., Link, A., Ali, G. S., Thomas, J., et al. (2012). Interactions of SR45, an SR-like protein, with spliceosomal proteins and an intronic sequence: insights into regulated splicing. Plant J. 71, 936-947. doi: 10.1111/j.1365-313X.2012.05042.x

Dou, K., Huang, C. F., Ma, Z. Y., Zhang, C. J., Zhou, J. X., Huang, H. W., et al. (2013). The PRP6-like splicing factor STA1 is involved in RNA-directed DNA methylation by facilitating the production of Pol V-dependent scaffold RNAs. Nucleic Acids Res. 41, 8489-8502. doi: 10.1093/nar/gkt639

Du, J. L., Zhang, S. W., Huang, H. W., Cai, T., Li, L., Chen, S., et al. (2015). The splicing factor PRP31 is involved in transcriptional gene silencing and stress response in Arabidopsis. Mol. Plant. 8, 1053-1068. doi: 10.1016/j. molp.2015.02.003 
Feng, J., Li, J., Gao, Z., Lu, Y., Yu, J., Zheng, Q., et al. (2015). SKIP confers osmotic tolerance during salt stress by controlling alternative gene splicing in Arabidopsis. Mol. Plant. 8, 1038-1052. doi: 10.1016/j.molp.2015.01.011

Figueroa, J. D., and Hayman, M. J. (2004). The human ski-interacting protein functionally substitutes for the yeast PRP45 gene. Biochem. Biophys. Res. Commun. 319, 1105-1109. doi: 10.1016/j.bbrc.2004.05.096

Filichkin, S., Priest, H. D., Megraw, M., and Mockler, T. C. (2015). Alternative splicing in plants: directing traffic at the crossroads of adaptation and environmental stress. Curr. Opin. Plant Biol. 24, 125-135. doi: 10.1016/j. pbi.2015.02.008

Gilchrist, D. A., Dos Santos, G., Fargo, D. C., Xie, B., Gao, Y., Li, L., et al. (2010). Pausing of RNA polymerase II disrupts DNA-specified nucleosome organization to enable precise gene regulation. Cell 143, 540-551. doi: 10.1016/j.cell.2010.10.004

Golovkin, M., and Reddy, A. S. (1996). Structure and expression of a plant U1 snRNP $70 \mathrm{~K}$ gene: alternative splicing of U1 snRNP 70K pre-mRNAs produces two different transcripts. Plant Cell. 8, 1421-1435. doi: 10.1105/tpc.8.8.1421

Golovkin, M., and Reddy, A. S. (1999). An SC35-like protein and a novel serine/ arginine-rich protein interact with Arabidopsis U1-70K protein. J. Biol. Chem. 274, 36428-36438. doi: 10.1074/jbc.274.51.36428

Hajheidari, M., Koncz, C., and Eick, D. (2013). Emerging roles for RNA polymerase II CTD in Arabidopsis. Trends Plant Sci. 18, 633-643. doi: 10.1016/j. tplants.2013.07.001

Hantsche, M., and Cramer, P. (2017). Conserved RNA polymerase II initiation complex structure. Curr. Opin. Struct. Biol. 47, 17-22. doi: 10.1016/j. sbi.2017.03.013

He, F., and Jacobson, A. (2015). Nonsense-mediated mRNA decay: degradation of defective transcripts is only part of the story. Annu. Rev. Genet. 49, 339-366. doi: 10.1146/annurev-genet-112414-054639

He, Y., and Amasino, R. M. (2005). Role of chromatin modification in floweringtime control. Trends Plant Sci. 10, 30-35. doi: 10.1016/j.tplants.2004.11.003

He, Y., Doyle, M. R., and Amasino, R. M. (2004). PAF1-complex-mediated histone methylation of FLOWERING LOCUS C chromatin is required for the vernalization-responsive, winter-annual habit in Arabidopsis. Genes Dev. 18, 2774-2784. doi: 10.1101/gad.1244504

Herzel, L., Ottoz, D. S. M., Alpert, T., and Neugebauer, K. M. (2017). Splicing and transcription touch base: co-transcriptional spliceosome assembly and function. Nat. Rev. Mol. Cell. Biol. 18, 637-650. doi: 10.1038/nrm.2017.63

Hou, X., Xie, K., Yao, J., Qi, Z., and Xiong, L. (2009). A homolog of human skiinteracting protein in rice positively regulates cell viability and stress tolerance. Proc. Natl. Acad. Sci. U.S.A. 106, 6410-6415. doi: 10.1073/pnas.0901940106

Hsin, J. P., and Manley, J. L. (2012). The RNA polymerase II CTD coordinates transcription and RNA processing. Genes Dev. 26, 2119-2137. doi: 10.1101/ gad.200303.112

Huang, C. F., Miki, D., Tang, K., Zhou, H. R., Zheng, Z., Chen, W., et al. (2013). A pre-mRNA splicing factor is required for RNA-directed DNA methylation in Arabidopsis. PLoS Genet. 9, e1003779. doi: 10.1371/journal.pgen.1003779

Jeronimo, C., and Robert, F. (2017). The mediator complex: at the nexus of RNA polymerase II transcription. Trends Cell Biol. 27, 765-783. doi: 10.1016/j. tcb.2017.07.001

Jones, M. A., Williams, B. A., McNicol, J., Simpson, C. G., Brown, J. W., and Harmer, S. L. (2012). Mutation of Arabidopsis spliceosomal timekeeper locus1 causes circadian clock defects. Plant Cell. 24, 4066-4082. doi: 10.1105/tpc.112.104828

Jonkers, I., and Lis, J. T. (2015). Getting up to speed with transcription elongation by RNA polymerase II. Nat. Rev. Mol. Cell. Biol. 16, 167-177. doi: 10.1038/ nrm3953

Keren, H., Lev-Maor, G., and Ast, G. (2010). Alternative splicing and evolution: diversification, exon definition and function. Nat. Rev. Genet. 11, 345-355. doi: $10.1038 / \operatorname{nrg} 2776$

Kouzarides, T. (2007). Chromatin modifications and their function. Cell 128, 695705. doi: 10.1016/j.cell.2007.02.005

Kwak, H., and Lis, J. T. (2013). Control of transcriptional elongation. Annu. Rev. Genet. 47, 483-508. doi: 10.1146/annurev-genet-110711-155440

Laduron, S., Deplus, R., Zhou, S., Kholmanskikh, O., Godelaine, D., De Smet, C., et al. (2004). MAGE-A1 interacts with adaptor SKIP and the deacetylase HDAC1 to repress transcription. Nucleic Acids Res. 32, 4340-4350. doi: 10.1093/nar/gkh735
Laloum, T., Martín, G., and Duque, P. (2018). Alternative splicing control of abiotic stress responses. Trends Plant Sci. 23, 140-150. doi: 10.1016/j. tplants.2017.09.019

Lawrence, M., Daujat, S., and Schneider, R. (2016). Lateral thinking: how histone modifications regulate gene expression. Trends Genet. 32, 42-56. doi: 10.1016/j. tig.2015.10.007

Lee, J. H., Ryu, H. S., Chung, K. S., Posé, D., Kim, S., Schmid, M., et al. (2013). Regulation of temperature-responsive flowering by MADS-box transcription factor repressors. Science 342, 628-632. doi: 10.1126/science.1241097

Lee, Y., and Rio, D. C. (2015). Mechanisms and regulation of alternative pre-mRNA splicing. Annu. Rev. Biochem. 84, 291-323. doi: 10.1146/ annurev-biochem-060614-034316

Li, B., Carey, M., and Workman, J. L. (2007). The role of chromatin during transcription. Cell 128, 707-719. doi: 10.1016/j.cell.2007.01.015

Li, Y., Xia, C., Feng, J., Yang, D., Wu, F., Cao, Y., et al. (2016). The SNW domain of SKIP is required for its integration into the spliceosome and its interaction with the Paf1 complex in Arabidopsis. Mol. Plant. 9, 1040-1050. doi: 10.1016/j. molp.2016.04.011

Li, Y., Yang, J., Shang, X. D., Lv, W. Z., Xia, C. C., Wang, C., et al. (2019). SKIP regulates environmental fitness and floral transition by forming two distinct complexes in Arabidopsis. New Phytol. 224, 321-335. doi: 10.1111/nph. 15990

Licatalosi, D. D., and Darnell, R. B. (2010). RNA processing and its regulation: global insights into biological networks. Nat. Rev. Genet. 11, 75-87. doi: $10.1038 / \mathrm{nrg} 2673$

Lim, G. H., Zhang, X., Chung, M. S., Lee, D. J., Woo, Y. M., Cheong, H. S., et al. (2010). A putative novel transcription factor, AtSKIP, is involved in abscisic acid signalling and confers salt and osmotic tolerance in Arabidopsis. New Phytol. 185, 103-113. doi: 10.1111/j.1469-8137.2009.03032.x

Mahrez, W., Shin, J., Muñoz-Viana, R., Figueiredo, D. D., Trejo-Arellano, M. S., Exner, V., et al. (2016). BRR2a affects flowering time via FLC splicing. PLoS Genet. 12, e1005924. doi: 10.1371/journal.pgen.1005924

Marquardt, S., Raitskin, O., Wu, Z., Liu, F., Sun, Q., and Dean, C. (2014). Functional consequences of splicing of the antisense transcript COOLAIR on FLC transcription. Mol. Cell. 54, 156-165. doi: 10.1016/j.molcel.2014.03.026

Matzke, M., Kanno, T., Daxinger, L., Huettel, B., and Matzke, A. J. (2009). RNAmediated chromatin-based silencing in plants. Curr. Opin. Cell. Biol. 21, 367376. doi: $10.1016 /$ j.ceb.2009.01.025

Michaels, S. D. (2009). Flowering time regulation produces much fruit. Curr. Opin. Plant Biol. 12, 75-80. doi: 10.1016/j.pbi.2008.09.005

Moore, M. J., and Proudfoot, N. J. (2009). Pre-mRNA processing reaches back to transcription and ahead to translation. Cell 136, 688-700. doi: 10.1016/j. cell.2009.02.001

Naftelberg, S., Schor, I. E., Ast, G., and Kornblihtt, A. R. (2015). Regulation of alternative splicing through coupling with transcription and chromatin structure. Annu. Rev. Biochem. 84, 165-198. doi: 10.1146/annurev-biochem-060614-034242

Oh, S., Zhang, H., Ludwig, P., and van Nocker, S. (2004). A mechanism related to the yeast transcriptional regulator Paflc is required for expression of the Arabidopsis FLC/MAF MADS box gene family. Plant Cell. 16, 2940-2953. doi: 10.1105/tpc.104.026062

Posé, D., Verhage, L., Ott, F., Yant, L., Mathieu, J., Angenent, G. C., et al. (2013). Temperature-dependent regulation of flowering by antagonistic FLM variants. Nature 503, 414-417. doi: 10.1038/nature 12633

Qüesta, J. I., Song, J., Geraldo, N., An, H., and Dean, C. (2016). Arabidopsis transcriptional repressor VAL1 triggers polycomb silencing at FLC during vernalization. Science 353, 485-488. doi: 10.1126/science.aaf7354

Reddy, A. S. (2007). Alternative splicing of pre-messenger RNAs in plants in the genomic era. Annu. Rev. Plant Biol. 58, 267-294. doi: 10.1146/annurev. arplant.58.032806.103754

Romera-Branchat, M., Andrés, F., and Coupland, G. (2014). Flowering responses to seasonal cues: what's new? Curr. Opin. Plant Biol. 21, 120-127. doi: 10.1016/j. pbi.2014.07.006

Sainsbury, S., Bernecky, C., and Cramer, P. (2015). Structural basis of transcription initiation by RNA polymerase II. Nat. Rev. Mol. Cell. Biol. 16, 129-143. doi: $10.1038 / \mathrm{nrm} 3952$

Saldi, T., Cortazar, M. A., Sheridan, R. M., and Bentley, D. L. (2016). Coupling of RNA polymerase II transcription elongation with pre-mRNA splicing. J. Mol. Biol. 428, 2623-2635. doi: 10.1016/j.jmb.2016.04.017 
Sanchez, S. E., Petrillo, E., Beckwith, E. J., Zhang, X., Rugnone, M. L., Hernando, C. E., et al. (2010). A methyl transferase links the circadian clock to the regulation of alternative splicing. Nature 468, 112-116. doi: 10.1038/nature09470

Schneider, C., Agafonov, E., Schmitzova, J., Hartmuth, K., Fabrizio, P., and Luhrmann, R. (2015). Dynamic contacts of U2, RES, Cwc25, Prp8 and Prp45 proteins with the pre-mRNA branch-site and $3^{\prime}$ splice site during catalytic activation and step 1 catalysis in yeast spliceosomes. PLoS Genet. 11, e1005539. doi: 10.1371/journal.pgen.1005539

Shim, J. S., Kubota, A., and Imaizumi, T. (2017). Circadian clock and photoperiodic flowering in Arabidopsis: CONSTANS is a hub for signal integration. Plant Physiol. 173, 5-15. doi: 10.1104/pp.16.01327

Song, Y. H., Shim, J. S., Kinmonth-Schultz, H. A., and Imaizumi, T. (2015). Photoperiodic flowering: time measurement mechanisms in leaves. Annu. Rev. Plant Biol. 66, 441-464. doi: 10.1146/annurev-arplant-043014-115555

Staiger, D., and Brown, J. W. (2013). Alternative splicing at the intersection of biological timing, development, and stress responses. Plant Cell. 25, 36403656. doi: 10.1105/tpc.113.113803

Syed, N. H., Kalyna, M., Marquez, Y., Barta, A., and Brown, J. W. (2012). Alternative splicing in plants-coming of age. Trends Plant Sci. 17, 616-623. doi: 10.1016/j. tplants.2012.06.001

Tessarz, P., and Kouzarides, T. (2014). Histone core modifications regulating nucleosome structure and dynamics. Nat. Rev. Mol. Cell. Biol. 15, 703-708. doi: $10.1038 / \mathrm{nrm} 3890$

Van Lijsebettens, M., and Grasser, K. D. (2014). Transcript elongation factors: shaping transcriptomes after transcript initiation. Trends Plant Sci. 19, 717726. doi: 10.1016/j.tplants.2014.07.002

Van Oss, S. B., Cucinotta, C. E., and Arndt, K. M. (2017). Emerging insights into the roles of the Pafl complex in gene regulation. Trends Biochem. Sci. 42, 788798. doi: 10.1016/j.tibs.2017.08.003

Voss, T. C., and Hager, G. L. (2014). Dynamic regulation of transcriptional states by chromatin and transcription factors. Nat. Rev. Genet. 15, 69-81. doi: $10.1038 / \mathrm{nrg} 3623$

Wahl, M. C., Will, C. L., and Luhrmann, R. (2009). The spliceosome: design principles of a dynamic RNP machine. Cell 136, 701-718. doi: 10.1016/j.cell.2009.02.009

Wang, X., Wu, F., Xie, Q., Wang, H., Wang, Y., Yue, Y., et al. (2012). SKIP is a component of the spliceosome linking alternative splicing and the circadian clock in Arabidopsis.. Plant Cell. 24, 3278-3295. doi: 10.1105/tpc.112.100081
Whittaker, C., and Dean, C. (2017). The FLC locus: a platform for discoveries in epigenetics and adaptation. Annu. Rev. Cell Dev. Biol. 33, 555-575. doi: 10.1146/annurev-cellbio-100616-060546

Yan, C., Hang, J., Wan, R., Huang, M., Wong, C. C., and Shi, Y. (2015). Structure of a yeast spliceosome at 3.6-angstrom resolution. Science 349, 1182-1191. doi: $10.1126 /$ science.aac7629

Yanovsky, M. J., and Kay, S. A. (2003). Living by the calendar: how plants know when to flower. Nat. Rev. Mol. Cell. Biol. 4, 265-275. doi: 10.1038/nrm1077

Yu, X., and Michaels, S. D. (2010). The Arabidopsis Paflc complex component CDC73 participates in the modification of FLOWERING LOCUS C chromatin. Plant Physiol. 153, 1074-1084. doi: 10.1104/pp.110.158386

Zhang, C. J., Zhou, J. X., Liu, J., Ma, Z. Y., Zhang, S. W., Dou, K., et al. (2013). The splicing machinery promotes RNA-directed DNA methylation and transcriptional silencing in Arabidopsis. EMBO J. 32, 1128-1140. doi: 10.1038/ emboj.2013.49

Zhang, X., Yan, C., Hang, J., Finci, L. I., Lei, J., and Shi, Y. (2017). An atomic structure of the human spliceosome. Cell 169, 918-929. doi: 10.1016/j. cell.2017.04.033

Zhang, X., Yan, C., Zhan, X., Li, L., Lei, J., and Shi, Y. (2018). Structure of the human activated spliceosome in three conformational states. Cell Res. 28, 307322. doi: 10.1038/cr.2018.14

Zhang, Y., Zhao, L., Li, H., Gao, Y., Li, Y., Wu, X., et al. (2013). GmGBP1, a homolog of human ski interacting protein in soybean, regulates flowering and stress tolerance in Arabidopsis. BMC Plant Biol. 13, 21. doi: $10.1186 / 1471-2229-13-21$

Conflict of Interest: The authors declare that the research was conducted in the absence of any commercial or financial relationships that could be construed as a potential conflict of interest.

Copyright (c) 2019 Cao and Ma. This is an open-access article distributed under the terms of the Creative Commons Attribution License (CC BY). The use, distribution or reproduction in other forums is permitted, provided the original author(s) and the copyright owner(s) are credited and that the original publication in this journal is cited, in accordance with accepted academic practice. No use, distribution or reproduction is permitted which does not comply with these terms. 